\title{
Rhodiola rosea: A Quantitative and Qualitative Assessment of Global Publications Output during 2003-18
}

\author{
K.K. Mueen Ahmed', B.M. Gupta ${ }^{2}$, Jivesh Bansal ${ }^{3}$, Madhu Bansal ${ }^{4, *}$ \\ 'Phcog.Net, Bengaluru, Karnataka, INDIA. \\ 2Formerly with CSIR-NISTADS, New Delhi, INDIA. \\ ${ }_{3}^{3}$ Panjab University, A.C. Joshi Library, Chandigarh, INDIA. \\ ${ }^{4}$ Panjab University, Department of Mathematics Library, Chandigarh, INDIA.
}

\section{ABSTRACT}

A quantitative and qualitative assessment of global research output (2016) on the "Rhodiola rosea" plant based on select bibliometric indicators, using Scopus database covering period 1993-2018, is presented here. Analyzed data on a series of bibliometric measures, like average annual growth, citations per paper, international collaborative papers, relative citation index, activity index, top productive countries, organizations, authors, journals and highly cited papers. The global publications registered an annual average growth rate of $12.97 \%$ and its citation impact averaged to 17.59 citations per paper. China and USA together account for more than $36 \%$ share of global output on Rhodiola rosea, whereas other 8 top ranking countries accounted each for global share between $4.06 \%$ and $7.60 \%$ during 2003-18. $83.04 \%$ global publication share and $89.95 \%$ global citation share has been contributed by top 10 countries during 2003-18. Sweden (2.78), Canada (1.17) and USA (1.11) registered the highest relative citation index among top 10 countries during 2003-18. Swedish Herbal Institute, Askloster, Sweden (21 papers), Medical University of Warsaw,
\end{abstract}

Poland (14 papers), Corvinus University of Budapest, Hungary were the three the most productive organizations and Z. Gyorgy and A. Panossian (18 papers each) and G. Wikman (14 papers) were the three top most productive authors. Phytomedicine (25 papers), Phytotherapy Research (21 papers) and Evidence-based Complementary and Alternate Medicine (15 papers) were the three leading journals contributing research in this area.

Key words: Rhodiola rosea, Medicinal plants, Global publications, Citations, International collaborative papers, Bibliometrics, Scientometrics. Correspondence

Madhu Bansal,

Department of Mathematics Library, Panjab University, Chandigarh, INDIA.

Phone no: +919465528460

Email: madhu@pu.ac.in

DOI: 10.5330/ijpi.2019.2.19

\section{INTRODUCTION}

Rhodiola rosea, is a botanical name of Roseroot crop (also called golden root, Arctic root, rose root, Rosavin, Rhidola, Aaron's rod, Rhidiola rhizome and solo). It grows primarily in dry sandy ground in cold and mountain regions of the world, including much of the Arctic, the mountains of Central Asia, scattered in eastern North America and parts of Europe. It grows on sea cliffs and on mountains at high altitude. It belongs to the stonecrop family named Crassulaceae, sub family of Sedoideae and genus Rhodiola. It is a perennial and fleshy succulent plant, which grows up to around $30 \mathrm{~cm} .{ }^{1,2}$

Typical uses of Rhodiola rosea are many. An extract of the root is used in cosmetic preparations as an antioxidant, astringent and skin conditioner. The dried root smells strongly of roses. They may be used to distill rosewater. The leaves and shoots are eaten raw or cooked like spinach and are sometimes added to salads. The plant is also grown as an ornamental, where it can be used as a ground cover. The roots of Rhodiola rosea are used as medicine. ${ }^{3}$

For centuries, Rhodiola rosea has been used in the traditional medicine of Russia, Scandinavia and other countries. Its use was first recorded by the Greek physician Dioscorides in $77 \mathrm{CE}$ in De Materia Medica. It has been used for centuries as a traditional medicine in Russia, Scandinavia and other countries for the treatment of fatigue, depression, anemia, impotence, GI ailments, infections and nervous system disorders and to promote physical endurance, longevity and work productivity. Rhodiola appeared in the scientific literature of Sweden, Norway, France, Germany, the Soviet Union and Iceland as early as 1725 . Rhodiola rosea has been an accepted medicine in Russia since 1969 for the treatment of fatigue, somatic and infectious illness, psychiatric and neurologic conditions and as a psychostimulant to increase memory, attention span and productivity in healthy individuals. It is also officially registered in Sweden and Denmark and is widely used in Scandinavia as a general tonic and to increase mental work ability under stress. ${ }^{4}$

About 140 chemical compounds are in the subterranean portions of Rhodiola rosea. It is classified as an adaptogen. It contains a range of antioxidant compounds and its adaptogenic activities are attributed to its unique phenylpropanoids rosavin, rosarin and rosidirin and to phenylethanol derivatives p-tyrosyl and salidroside (also called rhodioloside), as well as to flavonoids, triterpenes, monoterpenes and phenolic acids. Rosavins are the accepted marker compounds for water and alcohol extracts. ${ }^{1,4}$

The current medical and pharmacological texts describe its use as a stimulant good for fatigue, for somatic and infectious illnesses, in psychiatric and neurological conditions and in healthy individuals to relieve from fatigue and to increase attention span, memory and work productivity. Rhodiola rosea enhances learning and memory in animal models and increase 5-HT levels in the frontal cerebral cortex, promotes release of catecholamines that activate the cerebral cortex and the limbic system. Rhodiola rosea may prevent or ameliorate some age-related neurological dysfunctions. ${ }^{5,6}$

Research both from animal models and human clinical trials indicates a number of favorable effects associated with its use, including CNS 
stimulation, pronounced anti-stress effects, enhanced physical work and exercise performance, increased muscle strength, reduction in mental fatigue and prevention of high altitude sickness. Cardioprotective and anticancer effects also have been attributed to its intake. Rhodiola rosea extract exhibited an anti-inflammatory effect and protected muscle tissue during exercise. Studies have demonstrated its ability to induce a general sense of well-being and reduce situational anxiety. It has demonstrated improvement in depressive syndromes, mental and physical fatigues secondary to medical conditions, sexual dysfunction, thyroid hypofunction (without causing hyperthyroidism), thymus gland functioning, adrenal functioning and menopause-related conditions. Its mechanism of action is partly attributed to the herb's ability to influence levels of monoamines, including serotonin, dopamine and norepinephrine in the cerebral cortex, brainstem and hypothalamus through inhibition of degradation enzymes and facilitation of neurotransmitter support in the brain. It also appears to prevent catecholamine release and camp elevation in the myocardium, to prevent depletion of adrenal catecholamines by acute stress and to induce opioid peptide biosynthesis and activation of central and peripheral opioid receptors. Enhanced antitumor and antimetastatic activity has been demonstrated when Rhodiola rosea extract is combined with cyclophosphamide (an antitumor agent). ${ }^{7}$ The rose root imparts normalizing influences on adverse physical, chemical and biological disturbances but is otherwise innocuous. In India, the plant has been growing wild in the high altitudes of the Himalayas and known as solo. The Defence Research and Development Organization organization Defence Institute of High Altitude Research in India has taken on the responsibilities of its conservation, as well as the development of multiple management practices and the development of health foods, supplements and nutraceuticals with an aim of exploring and putting to good use, the limited flora and vegetation found in this cold arid zone. Considering the hilly terrains and a difficult lifestyle with significantly low levels of atmospheric oxygen, nutritive foods for sustenance of energy are an absolute must in the mountains, Rhodiola rosea has been shown to possess properties of mitigating the harmful gamma radiations, which are typically released during warfare. A certain phytochemical from this plant has been used in the management of high-altitude sickness. For a hilly terrain like Ladakh and Leh, where neuro-protection and biological tissue regeneration are always desirable, this particular species of Rhodiola may prove to be very beneficial. ${ }^{8}$

No scientometric study had been carried out in the past on Rhodiola rosea plant. However, few other research studies are available, which quantitatively and qualitatively analyze global and Indian literature on individual medicinal plants, including on Aloe vera, ${ }^{9}$ Azadrachta indica, ${ }^{10}$ Curcuma longa, ${ }^{11}$ Glycyrrhiza glabre, ${ }^{12}$ Nigella sativa, ${ }^{13}$ Ocimum santum, ${ }^{14}$ Phyllanthis emblica, ${ }^{15}$ Tinospora cordifolia ${ }^{16}$ and Withania somnifera. ${ }^{17}$

The present study analyses the performance of global research on Rhodiola rosea plant, based on publications output indexed in Scopus database during 1993-2018. In particular, it studied the distribution of global publication output of the world and of 10 most productive countries, by document type and source type, growth rate of its annual and cumulative output, the share of international collaborative publications, broad subject-wise scatter across sub-fields, identification of significant keywords depicting trends in research, publication output and share and citation impact of its top 15 global organizations, authors and journals, identification of leading journals and characteristics of its high cited publications.

\section{METHODS}

Rhodiola rosea plant publications for the present study was derived from the Scopus database (http://www.scopus.com) covering the period 2003-
18. Keywords, such as "Rhodiola rosea" was searched in "Keyword" and "Title of Paper" tags during the period 2003-18 to get publication data on global output on Rhodiola rosea plant (566 records) during this period. For specific information on global publication data on "Rhodiola rosea", this search string was further restricted to individual country by name in "country tag" one by one to ascertain publication output of top 10 most productive countries (including India). The search search string was subsequently refined, using analytical tags in Scopus database, by "subject area tag", "country tag", "source title tag", "journal title name" and "affiliation tag", to get data/information on the distribution of publications output by subject, collaborating countries, author-wise, organization-wise and journal-wise, etc. For citation data, citations to publications were also collected from date of publication till 20 August 2019.

(KEY ("Rhodiola rosea") OR TITLE (“Rhodiola rosea”)) AND PUBYEAR $>2002$ AND PUBYEAR $<2019$

\section{ANALYSIS}

Rhodiola rosea global research publication output cumulated to 566 publications during 2003-18. Its annual publications increased from 14 in the year 2003 to 47 in the year 2018, registering $12.97 \%$ growth per annum. The maximum research output (50) was in the year 2012 and minimum (14) in the year 2003. The cumulative publication output of Rhodiola rosea increased from 211 in 8 years (2003-10) to 355 publications during succeeding eight-year period 2011-18, registering $68.25 \%$ growth. The global publications citation impact of Rhodiola rosea plant averaged to 17.59 Citations Per Publication (CPP) during 2003-18; its eight-yearly citation impact, however, averaged to $29.57 \mathrm{CPP}$ for the period 2003-10, which sharply declined to 10.46 CPP for the period 2011-18 (Table 1). Of the total global publications output, 77.21 (437) appeared as articles, $14.84 \%$ (84) as reviews, $1.94 \%$ (11) as notes, $1.59 \%$

\section{Table 1: Rhodiola rosea Plant Annual Publications during 2003-18.}

\begin{tabular}{|c|c|c|c|}
\hline \multirow[t]{2}{*}{ Publication Period } & \multicolumn{3}{|c|}{ World } \\
\hline & TP & TC & CPP \\
\hline 2003 & 14 & 451 & 32.21 \\
\hline 2004 & 16 & 470 & 29.38 \\
\hline 2005 & 15 & 570 & 38.00 \\
\hline 2006 & 21 & 598 & 28.48 \\
\hline 2007 & 25 & 688 & 27.52 \\
\hline 2008 & 31 & 707 & 22.81 \\
\hline 2009 & 55 & 1758 & 31.96 \\
\hline 2010 & 34 & 997 & 29.32 \\
\hline 2011 & 38 & 767 & 20.18 \\
\hline 2012 & 50 & 977 & 19.54 \\
\hline 2013 & 58 & 714 & 12.31 \\
\hline 2014 & 44 & 386 & 8.77 \\
\hline 2015 & 30 & 341 & 11.37 \\
\hline 2016 & 48 & 286 & 5.96 \\
\hline 2017 & 40 & 179 & 4.48 \\
\hline 2018 & 47 & 65 & 1.38 \\
\hline 2003-11 & 211 & 6239 & 29.57 \\
\hline $2012-18$ & 355 & 3715 & 10.46 \\
\hline 2003-18 & 566 & 9954 & 17.59 \\
\hline
\end{tabular}

TP=Total Papers; TC=Total Citations; $\mathrm{CPP}=$ Citations Per Paper 
Table 2: Global Publication Output and Share of Top 10 Countries on Rhodiola rosea during 2003-18.

\begin{tabular}{|c|c|c|c|c|c|c|c|c|c|c|c|c|}
\hline \multirow[t]{2}{*}{ S.No } & \multirow[t]{2}{*}{ Name of the Country } & \multicolumn{3}{|c|}{ Number of Papers } & \multicolumn{3}{|c|}{ Share of Papers } & \multirow[t]{2}{*}{ TC } & \multirow[t]{2}{*}{ CPP } & \multirow[t]{2}{*}{ ICP } & \multirow[t]{2}{*}{$\% I C P$} & \multirow[t]{2}{*}{$\mathrm{RCl}$} \\
\hline & & $2003-10$ & 2011-18 & 2003-18 & 2003-10 & 2011-18 & 2003-18 & & & & & \\
\hline 1 & China & 28 & 93 & 121 & 13.27 & 26.20 & 21.38 & 1908 & 15.77 & 18 & 14.88 & 0.90 \\
\hline 2 & USA & 27 & 57 & 84 & 12.80 & 16.06 & 14.84 & 1644 & 19.57 & 43 & 51.19 & 1.11 \\
\hline 3 & Russia Federation & 22 & 21 & 43 & 10.43 & 5.92 & 7.60 & 589 & 13.70 & 10 & 23.26 & 0.78 \\
\hline 4 & Italy & 10 & 31 & 41 & 4.74 & 8.73 & 7.24 & 682 & 16.63 & 7 & 17.07 & 0.95 \\
\hline 5 & Germany & 14 & 23 & 37 & 6.64 & 6.48 & 6.54 & 658 & 17.78 & 26 & 70.27 & 1.01 \\
\hline 6 & Sweden & 18 & 16 & 34 & 8.53 & 4.51 & 6.01 & 1663 & 48.91 & 21 & 61.76 & 2.78 \\
\hline 7 & Poland & 15 & 18 & 33 & 7.11 & 5.07 & 5.83 & 462 & 14.00 & 9 & 27.27 & 0.80 \\
\hline 8 & Canada & 13 & 17 & 30 & 6.16 & 4.79 & 5.30 & 618 & 20.60 & 12 & 40.00 & 1.17 \\
\hline 9 & Taiwan & 5 & 19 & 24 & 2.37 & 5.35 & 4.24 & 327 & 13.63 & 5 & 20.83 & 0.77 \\
\hline \multirow[t]{4}{*}{10} & U.K. & 2 & 21 & 23 & 0.95 & 5.92 & 4.06 & 403 & 17.52 & 15 & 65.22 & 1.00 \\
\hline & Total & 154 & 316 & 470 & 72.99 & 89.01 & 83.04 & 8954 & 19.05 & 166 & 35.32 & 1.08 \\
\hline & World & 211 & 355 & 566 & & & & 9954 & 17.59 & & & \\
\hline & $\begin{array}{c}\text { Share of } 10 \text { Countries in } \\
\text { World Total }\end{array}$ & 72.99 & 89.01 & 83.04 & & & & 89.95 & & & & \\
\hline
\end{tabular}

(9) as conference papers, $1.41 \%$ (8) as editorials, $1.06 \%$ (6) each as short surveys and erratum, $0.71 \%(4)$ as book chapters and $0.18 \%(1)$ as letter.

\section{Leading Countries Research Output on Rhodiola rosea}

The Rhodiola rosea research output had originated from 58 countries during 2003-18, of which, 32 published 1-5 papers each, 9 countries 6-10 papers each, 7 countries 11-20 papers each, 8 countries 21-50 papers each and 2 countries $84-121$ papers. The top 10 most productive countries have contributed 23 to 121 publications each on Rhodiola rosea during 2003-18 (Table 2). The 10 leading countries on Rhodiola rosea research together accounted for $83.04 \%$ global publication share and 89.95\% citation share during 2003-18; it however accounted for $72.99 \%$ global publication share during 2003-10 which increased to $89.01 \%$ during succeeding eight-year period 2011-18. Country-wise, the global publication share of 10 leading countries varied widely $5.92 \%$ to $26.20 \%$ during 2003-18, with China accounting for the highest publication share (21.38\%), followed by USA (14.84\%), Russia Federation, Italy, Germany and Sweden (6.01\% to $7.60 \%$ ) and other 4 countries from $4.06 \%$ to $5.83 \%$ during 2003-18. The global publications registered a increasing publication share in China, U.K., Italy, USA and Taiwan (from 2.98\% to 12.93\%), as against decrease in Germany, Canada, Poland, Sweden and Russian Federation (from $0.16 \%$ to $4.51 \%$ ) in eight years period (2003-10 and 2011-18). Three of the 10 leading countries scored relative citation index above the world average of 1.08: Sweden (2.78), Canada (1.17) and USA (1.11) during 2003-18. India has comparatively contributed only 16 papers, ranked $14^{\text {th }}$ in world output and registered citation per paper of 13.69 , its performance in terms of relative citation index has below the world average (0.78).

\section{International Collaboration}

The international collaborative output of 10 leading countries on Rhodiola rosea research as a national share in the country-wise output varied widely from $14.78 \%$ (China) to $70.27 \%$ (Germany), with average share of $35.32 \%$ during 2003-18. Most surprisingly, India's international collaborative share in its national output in Rhodiola rosea research was comparatively small, $12.50 \%$.

\section{Subject-Wise Distribution of Research Output}

According to the Scopus classification, the Rhodiola rosea global research output published during 2003-18 is distributed across seven sub-fields as per Scopus classification. The medicine accounted for the highest publications share $(44.88 \%)$, followed by pharmacology, toxicology and pharmaceutics (37.63\%), biochemistry, genetics and molecular biology (32.69\%), agricultural and biological sciences (21.02\%), chemistry (12.72\%), immunology and microbiology (6.18\%) and neurosciences (4.77) during 2003-18. Its activity index, which computes change in research activity in the discipline over time 2003-10 to 2011-18 (world average activity index of a given subject is taken as 100), witnessed increase in biochemistry, genetics and molecular biology (from 97.15 to 101.69), agricultural and biological sciences (from 81.15 to 111.20), immunology and microbiology (from 84.31 to 109.33 ) and neurosciences (from 79.48 to 112.20), as against decline of research activity in medicine (from 102.44 to 98.55), pharmacology, toxicology and pharmaceutics (from 103.27 to 98.06) and chemistry (from 115.49 to 90.79) from 2003-10 to 2011-18. Neuroscience, among various subjects registered the highest citations impact per paper of $32.52 \mathrm{CPP}$, followed by biochemistry, genetics and molecular Biology (22.16), pharmacology, toxicology and pharmaceutics (21.22), chemistry (19.29), medicine (18.74), immunology and microbiology (13.29) and agricultural and biological sciences (10.84) during 2003-18 (Table 3).

\section{Profile of Top 15 Most Productive Global Organizations}

Two hundred forty-eight (248) organizations participated in global Rhodiola rosea research during 2003-18, of which 230 organizations contributed 1-5 papers each, 13 organizations 6-10 papers each and 5 organizations 11-21 papers each.

The productivity of top 15 most productive global organizations in Rhodiola rosea research varied from 5 to 21 publications and together they contributed $24.03 \%$ (136) global publication share and $36.32 \%$ (3615) global citation share during 2003-18. The scientometric profile of these top 15 organizations is presented in Table 4.

- Six of these organizations registered publications output greater than the group average of 
Table 3: Rhodiola rosea Global Publications Distribution by Subjects during 2003-18.

\begin{tabular}{|c|c|c|c|c|c|c|c|c|c|}
\hline \multirow[t]{2}{*}{ S.No } & \multirow[t]{2}{*}{ Subject* } & \multicolumn{3}{|c|}{ Number of Papers (TP) } & \multicolumn{2}{|c|}{ Activity Index } & TC & CPP & \%TP \\
\hline & & 2003-10 & 2011-18 & 2003-18 & 2003-10 & 2011-18 & \multicolumn{3}{|c|}{ 2003-18 } \\
\hline 1 & Medicine & 97 & 157 & 254 & 102.44 & 98.55 & 4759 & 18.74 & 44.88 \\
\hline 2 & Pharmacology, Toxicology and Pharmaceutics & 82 & 131 & 213 & 103.27 & 98.06 & 4520 & 21.22 & 37.63 \\
\hline 3 & Biochemistry, Genetics and Molecular Biology & 67 & 118 & 185 & 97.15 & 101.69 & 4100 & 22.16 & 32.69 \\
\hline 4 & Agricultural and Biological Sciences & 36 & 83 & 119 & 81.15 & 111.20 & 1290 & 10.84 & 21.02 \\
\hline 5 & Chemistry & 31 & 41 & 72 & 115.49 & 90.79 & 1389 & 19.29 & 12.72 \\
\hline 6 & Immunology and Microbiology & 11 & 24 & 35 & 84.31 & 109.33 & 465 & 13.29 & 6.18 \\
\hline \multirow[t]{2}{*}{7} & Neuroscience & 8 & 19 & 27 & 79.48 & 112.20 & 878 & 32.52 & 4.77 \\
\hline & World Output & 211 & 355 & 566 & 100.00 & 100.00 & 9954 & 17.59 & \\
\hline
\end{tabular}

- There is overlapping of literature covered under various subjects

TP=Total Papers; TC=Total Citations; $\mathrm{CPP}=$ Citations Per Paper.

Table 4: Top 15 Most Productive Global Organizations: Cientometric Profile on Rhodiola rosea Research during 2003-18.

\begin{tabular}{|c|c|c|c|c|c|c|c|c|}
\hline S. No & Name of the Organization & TP & TC & CPP & HI & ICP & \%ICP & $\mathrm{RCl}$ \\
\hline 1 & Swedish Herbal Institute, Askloster, Sweden & 21 & 1503 & 71.57 & 18 & 17 & 80.95 & 4.07 \\
\hline 2 & Medical University of Warshaw, Poland & 14 & 350 & 25.00 & 11 & 5 & 35.71 & 1.42 \\
\hline 4 & University of Oulu, Finland & 11 & 305 & 27.73 & 8 & 1 & 9.09 & 1.58 \\
\hline 5 & University of California, Irvine, USA & 10 & 173 & 17.30 & 4 & 1 & 10.00 & 0.98 \\
\hline 8 & University of Ottawa, Canada & 8 & 104 & 13.00 & 6 & 2 & 25.00 & 0.74 \\
\hline 9 & Institute of Biodiversity and Ecosystem Research, Bulgarian Academy of Sciences & 7 & 69 & 9.86 & 5 & 1 & 14.29 & 0.56 \\
\hline 10 & China Medical University, Taichung, Taiwan & 6 & 99 & 16.50 & 4 & 5 & 83.33 & 0.94 \\
\hline 11 & Institute of Organic Chemistry with Center of Phytochemistry 10CCP, Bulgaria & 6 & 28 & 4.67 & 3 & 0 & 0.00 & 0.27 \\
\hline \multirow[t]{4}{*}{15} & China Pharmaceutical University, China & 5 & 81 & 16.20 & 3 & 0 & 0.00 & 0.92 \\
\hline & Total of 15 organizations & 136 & 3615 & 26.58 & 6.07 & 48.00 & 35.29 & 1.51 \\
\hline & Total of World & 566 & 9954 & 17.59 & & & & \\
\hline & Share of top 15 organizations in World total output & 24.03 & 36.32 & & & & & \\
\hline
\end{tabular}

TP=Total Papers; TC=Total Citations; $\mathrm{CPP}=$ Citations Per Paper; HI=h-index; ICP=International Collaborative Papers; RCI=Relative Citation Index.

- 9.06: Swedish Herbal Institute, Askloster, Sweden (21 papers), Medical University of Warsaw, Poland (14 papers), Corvinus University of Budapest, Hungary and University of Oulu, Finland (11 papers each), University of California, Irvine, USA and University of Camerino, Italy (10 papers each) during 2003-18.

- Four organizations registered citation impact above the group average of 36.58 citations per publication and relative citation index of 1.51 during 2004-18: Swedish Herbal Institute, Askloster, Sweden (71.57 and 4.07), Jiangnan University, China (33 and 1.88), University of Camerino, Italy (32.0 and 1.82) and University of Oulu, Finland (37.73 and 9.09).

- Six organizations contributed international collaborative publications share above the group average of $35.29 \%$ : China Medical University, Taichung, Taiwan (83.33\%), Swedish Herbal Institute, Askloster, Sweden (80.95\%), Corvinus University of Budapest, Hungary (63.64\%), University of Copenhagen, Denmark and The
Norwegian Institute of Bioeconomy (50\% each) and Medical University of Warsaw, Poland (35.71\%) during 2003-18.

\section{Profile of Top 15 Most Productive Authors}

Three Hundred Seven (307) authors participated in global Rhodiola rosea research during 2003-18, of which 284 authors contributed 1-5 papers each, 20 authors 6-10 papers each and 3 authors 11-187 papers each.

The research productivity in the field of Rhodiola rosea research of top 15 most productive authors varied from 7 to 18 publications. Together they contributed $25.62 \%$ (145) global publication share and $42.08 \%$ (4189) global citation share during 1993-18. The scientometric profile of these 15 authors is presented in Table 5.

- Four authors registered publications output above the group average of 9.67: Z. Gyorgy and A. Panossian (18 papers each), G. Wikman (14 papers) and A. Hohtola (10 papers) during 2003-18.

- Five authors registered citation impact above the group average of 28.89 citations per publication and relative citation index of 1.64 : 
Table 5: Top 15 Most Productive Authors: Scientometric Profile on Rhodiola rosea during 2003-18.

\begin{tabular}{|c|c|c|c|c|c|c|c|c|c|}
\hline \multirow[t]{2}{*}{ S. No } & Name of the & & \multirow[t]{2}{*}{ TP } & \multirow[t]{2}{*}{ TC } & \multirow[t]{2}{*}{ CPP } & \multirow[t]{2}{*}{ HI } & \multirow[t]{2}{*}{ ICP } & \multirow[t]{2}{*}{$\% \mid C P$} & \multirow[t]{2}{*}{$\mathrm{RCl}$} \\
\hline & Author & & & & & & & & \\
\hline 1 & Z. Gyorgy & University of Oulu, Finland & 18 & 123 & 6.83 & 7 & 13 & 72.22 & 0.39 \\
\hline 2 & Panossian & Swedish Herbal Institute, Sweden & 18 & 1155 & 64.17 & 15 & 14 & 77.78 & 3.65 \\
\hline 3 & G. Wikman & Swedish Herbal Institute, Sweden & 14 & 939 & 67.07 & 14 & 12 & 85.71 & 3.81 \\
\hline 4 & Hohtola & University of Oulu, Finland & 10 & 187 & 18.70 & 7 & 1 & 10.00 & 1.06 \\
\hline 5 & Tolonen & University of Oulu, Finland & 9 & 180 & 20.00 & 6 & 1 & 11.11 & 1.14 \\
\hline 6 & J.T. Arnason & University of Ottawa, Canada & 8 & 99 & 12.38 & 5 & 2 & 25.00 & 0.70 \\
\hline 7 & L. Hu & Air Force College, Xuzhou, China & 8 & 166 & 20.75 & 5 & 0 & 0.00 & 1.18 \\
\hline 8 & C. Ma & Jiangnan University, Wuxi, China & 8 & 166 & 20.75 & 5 & 0 & 0.00 & 1.18 \\
\hline 9 & L. Mattioli & University of Camerino, Italy & 8 & 281 & 35.13 & 8 & 1 & 12.50 & 2.00 \\
\hline 10 & M. Perfumi & University of Camerino, Italy & 8 & 279 & 34.88 & 8 & 1 & 12.50 & 1.98 \\
\hline 11 & H. Wang & Jiangnan University, Wuxi, China & 8 & 166 & 20.75 & 5 & 0 & 0.00 & 1.18 \\
\hline 12 & Cuerrier & University of Montreal, Canada & 7 & 52 & 7.43 & 4 & 3 & 42.86 & 0.42 \\
\hline 13 & M. Furmanova & Medical University of Warshaw, Poland & 7 & 205 & 29.29 & 5 & 4 & 57.14 & 1.66 \\
\hline 14 & M. Jafari & University of Calfornia, Irvine, USA & 7 & 168 & 24.00 & 4 & 0 & 0.00 & 1.36 \\
\hline \multirow[t]{4}{*}{15} & A, Pedryc Cornivas & University of Budapest, Hungry & 7 & 23 & 3.29 & 3 & 5 & 71.43 & 0.19 \\
\hline & & Total of 15 authors & 145 & 4189 & 28.89 & 6.73 & 57 & 39.31 & 1.64 \\
\hline & & Total of World & 566 & 9954 & 17.59 & & & & \\
\hline & & Share of top 15 authors in World total output & 25.62 & 42.08 & & & & & \\
\hline
\end{tabular}

TP=Total Papers; TC=Total itations; CPP=Citations Per Paper; HI=h-index; ICP=International Collaborative Papers; RCI=Relative Citation Index.

G. Wikman (67.07 and 3.81), A. Panossian (64.17 and 3.65), L. Mattioli (35.13 and 2.00), M. Perfumi (34.88 and 1.98) and M. Furmanova (29.29 and 1.6) during 2003-18.

- Six authors contributed international collaborative publications share above the group average of $39.31 \%$ of all authors: G. Wikman (85.71\%), A. Panossian (77.78\%), Z. Gyorgy (7.2.22\%), A, Pedryc Cornivas (71.43\%), M. Furmanova (57.14\%) and A. Cuerrier (42.86\%) during 2003-18.

\section{Medium of Research Communication}

Of the total global output on Rhodiola rosea research, 96.11\% (544) appeared in journals, $2.83 \%$ (16) in book series, $0.53 \%$ (3) in books, $0.35 \%$ (2) as trade publications and $0.18 \%$ (1) in conference proceeding during 2003-18. 544 journal papers appeared in 326 journals, of which 316 journals published 1-5 papers each, 5 journals 6-10 papers each, 3 journals 11-20 papers each and 2 journals 21-25 papers each during 2003-18. The top 15 most productive journals reported 4 to 25 papers each on Rhodiola rosea research; together they accounted for $26.65 \%$ (141 papers) of total Rhodiola rosea output published in journals during 2003-18, shown increase from $23.30 \%$ to $28.70 \%$ share between $2003-10$ and 2011-18. The top ranking journal is Phytomedicine (with 25 papers), followed by Phytotherapy Research (21 papers), Evidence-based Complementary and Alternate Medicine (15 papers), Acta Horticulturae (13 papers), Planta Medica (11 papers), etc. during 2003-18 (Table 6).

\section{Significant Keywords}

77 significant keywords have been identified from the literature which through light on the research trends in Rhodiola rosea plant research including on its chemical composition, biological and pharmacological activity, traditional and official use of Rhodiola rosea L. in medicine. These keywords are listed in Table 7 in the decreasing order of the frequency of their occurrence in the literature during 2003-18.

\section{Highly Cited Papers}

Fourteen highly cited papers were identified each having 105 to 249 citations (13 papers each in citation range 105-200 and 1 paper with 249 citations) in 16 years during 2003-18. Together these 14 papers cumulated a total of 2029 citations, averaging 144.9 citations per paper. Of the 14 highly cited papers, 5 resulted from the participation of research organizations in their role as stand-alone (non-collaborating) institutional authors and remaining 9 from two or more research organizations working in their role as collaborating partners per paper (3 national collaborative and 6 international collaborative). Among 14 highly cited papers, the largest participation was seen from Sweden (7 papers), followed by Australia (3 papers) and Armenia, Canada, China, Germany, Italy, Morocco, Netherlands, Russian Federation, Spain and Switzerland (1 paper each). These 14 highly cited papers involved the participation of 59 personal authors and 32 research organizations in total across globe. Of the 14 highly cited papers, 9 were published as articles and 5 as review papers. These 14 highly cited papers were published in 11 journals, with 3 papers in Phytotherapy Research, 2 papers in Phytomedicine and 1 paper each in Biogerontology, Current Diabetes Review, Ecological Engineering, European Neuropsychpharmacology, Expert Opinion in Therapeutic Targets, Journal of Ethnopharmacology, Neurochemistry International, Nordic Journal of Psychiatry and Planta Medica.

\section{CONCLUSION}

The global publication data on Rhodiola rosea during the last 16 years showed that the annual and eight-year cumulative global output of Rhodiola rosea research registered $12.97 \%$ and $68.25 \%$ growth. Its global citation impact averaged to 17.59 citations per paper (CPP) in 16 years, which decreased from 29.57 CPP to 10.47 CPP from 2003-10 to 2011-18. The data for the study has been derived from the Scopus database with a view to study its quantitative and qualitative aspects. 
Table 6: Top 15 Most Productive Journals Publishing on Rhodiola rosea during 2003-18.

\begin{tabular}{|c|c|c|c|c|}
\hline \multirow[t]{2}{*}{ S.No } & \multirow[t]{2}{*}{ Name of the Journal } & \multicolumn{3}{|c|}{ Number of Papers } \\
\hline & & 2003-10 & 2011-18 & 2003-18 \\
\hline 1 & Phyomedicine & 8 & 17 & 25 \\
\hline 2 & Phytotherapy Research & 12 & 9 & 21 \\
\hline 3 & Evidence-based Complementary and Alternate Medicine & 2 & 13 & 15 \\
\hline 4 & Acta Horticulturae & 2 & 11 & 13 \\
\hline 5 & Planta Medica & 5 & 6 & 11 \\
\hline 6 & Bulletin of Experimental Biology and Medicine & 1 & 7 & 8 \\
\hline 7 & Journal of Ethnopharmacology & 3 & 6 & 9 \\
\hline 8 & Central European Journal of Immunlogy & 6 & 0 & 6 \\
\hline 9 & Food and Chemical Toxicology & 0 & 6 & 6 \\
\hline 10 & Zeitscrift Fur Phytotherapie & 0 & 6 & 6 \\
\hline 11 & Biomedical Chromatography & 3 & 3 & 6 \\
\hline 12 & Pharmaceutical Biology & 3 & 2 & 5 \\
\hline 13 & Pharmaceutical Chemistry Journal & 3 & 2 & 5 \\
\hline 14 & PLOS One & 0 & 5 & 5 \\
\hline \multirow[t]{4}{*}{15} & Acta Scientiarum Hortorum Cultus & 0 & 4 & 4 \\
\hline & Total of 15 journals & 48 & 97 & 145 \\
\hline & Total global journal output & 206 & 338 & 544 \\
\hline & Share of top 15 journals in global journal output & 23.30 & 28.70 & 26.65 \\
\hline
\end{tabular}

More than 36\% share of global output on Rhodiola rosea were from China and USA combined, whereas other 8 top ranking countries accounted each for global share between 4.06\% and 7.60\% during 2003-18. The top 10 most productive countries in Rhodiola rosea research together accounted for $83.04 \%$ global publication share and $89.95 \%$ global citation share during 2003-18. The global publication share of Rhodiola rosea, however, increased from $72.99 \%$ to $89.01 \%$ from $2003-10$ to $2011-18$. The global publication share registered an increase in China, U.K., Italy, USA and Taiwan (from $2.98 \%$ to $12.93 \%$ ), as against decrease in Germany, Canada, Poland, Sweden and Russian Federation (from 0.16\% to $4.51 \%$ ) in eight years period (2003-10 and 2011-18). Of the top 10 countries, three registered relative citation index above the world average of 1.08: Sweden (2.78), Canada (1.17) and USA (1.11) during 2003-18. The international collaborative output of top 10 most productive countries in Rhodiola rosea research varied widely from $14.78 \%$ (China) to $70.27 \%$ (Germany) during 2003-18.

Medicine was the most sought after subject area of Rhodiola rosea research accounting for $(44.88 \%)$ the highest publications share, followed by pharmacology, toxicology and pharmaceutics (37.63\%), biochemistry, genetics and molecular biology (32.69\%), agricultural and biological sciences $(21.02 \%)$, chemistry (12.72\%), immunology and microbiology (6.18\%) and neurosciences (4.77) during 2003-18. The research activities registered increase in biochemistry, genetics and molecular biology, agricultural and biological sciences, immunology and microbiology and neurosciences, as against decline of research activity in medicine, pharmacology, toxicology and pharmaceutics and chemistry (from 115.49 to 90.79 ) from 2003-10 to 2011-18 Neuroscience, among various subjects registered the highest citations impact per paper of $32.52 \mathrm{CPP}$, followed by biochemistry, genetics and molecular Biology, pharmacology, toxicology and pharmaceutics, chemistry, medicine, immunology and microbiology and agricultural and biological sciences during 2003-18.

The top 15 most productive research organizations and the authors on Rhodiola rosea research collectively contributed $24.03 \%$ and $25.62 \%$ global publication share and $36.32 \%$ and $42.08 \%$ global citation share respectively during 2003-18. The leading organizations in terms of publication productivity were: Swedish Herbal Institute, Askloster, Sweden (21 papers), Medical University of Warsaw, Poland (14 papers), Corvinus University of Budapest, Hungary and University of Oulu, Finland (11 papers each), University of California, Irvine, USA and University of Camerino, Italy (10 papers each) during 2003-18. The leading organizations in terms of citation impact per paper and relative citation index were: Swedish Herbal Institute, Askloster, Sweden (71.57 and 4.07), Jiangnan University, China (33 and 1.88), University of Camerino, Italy (32.0 and 1.82) and University of Oulu, Finland (37.73 and 9.09). Similarly, the leading authors in terms of publication productivity were: Z. Gyorgy and A. Panossian (18 papers each), G. Wikman (14 papers) and A. Hohtola (10 papers) during 2003-18. The leading authors in terms of citation impact per paper and relative citation index were: G. Wikman (67.07 and 3.81), A. Panossian (64.17 and 3.65), L. Mattioli (35.13 and 2.00), M. Perfumi (34.88 and 1.98) and M. Furmanova (29.29 and 1.6) during 2003-18.

The journals medium accounted for $96.11 \%$ global share in Rhodiola rosea research with top 15 most productive journals accounting for $26.65 \%$ of total publications output in journals during 2003-18. Phytomedicine contributed the largest number of papers (25), followed by Phytotherapy Research (21 papers), Evidence-based Complementary and Alternate Medicine (15 papers), Acta Horticulturae (13 papers), Planta Medica (11 papers), etc. during 2003-18

Of the total Rhodiola rosea global research output, only 14 publications registered high citations, in the range of 105-249 citations per paper and collectively these highly cited papers received a total of 2029 citations, averaging to 144.9 citations per paper. These 14 highly cited papers involved the participation of 59 authors and 32 organizations and were published in 117 journals, of which with 3 papers in Phytotherapy Research, 2 papers in Phytomedicine and 1 paper each in 9 other journals. Concludes that further R\&D studies on Rhodiola rosea are needed globally and in India with an aim to explore its cultivation and conservation 
Table 7: List of Significant Keywords on Global Rhodiola rosea Research Literature during 2003-18.

\begin{tabular}{|c|c|c|c|c|c|}
\hline S.No & Keyword & Frequency & S.No & Keyword & Frequency \\
\hline 1 & Rhodiola rosea & 392 & 41 & Adaptogen & 26 \\
\hline 2 & Rhodiola & 283 & 42 & Anti-inflammation Agent & 26 \\
\hline 3 & Plant Extracts & 260 & 43 & Diabetes & 26 \\
\hline 4 & Salidroside & 133 & 44 & Fluoxetine & 26 \\
\hline 5 & Medicinal Plants & 107 & 45 & Anxiety Disorders & 25 \\
\hline 6 & Drug Effects & 94 & 46 & Insomnia & 25 \\
\hline 7 & Chemistry & 87 & 47 & Stress & 25 \\
\hline 8 & Phytotherapy & 84 & 48 & Fluoxetine & 23 \\
\hline 9 & Herbaceous Agent & 81 & 49 & Gene Expression & 23 \\
\hline 10 & Drug Efficacy & 74 & 50 & In vivo Study & 23 \\
\hline 11 & Depression & 71 & 51 & Physiology & 23 \\
\hline 12 & Phenols & 68 & 52 & Mental Diseases & 22 \\
\hline 13 & Rosavin & 68 & 53 & Flavanoids & 21 \\
\hline 14 & Plant Root & 68 & 54 & Drug Isolation & 20 \\
\hline 15 & Glycosides & 63 & 55 & Molecular Structure & 20 \\
\hline 16 & Antioxidant Activity & 61 & 56 & Pathology & 20 \\
\hline 17 & Drug Mechanism & 59 & 57 & Ageing & 10 \\
\hline 18 & Rhodiolside & 59 & 58 & Herbs & 19 \\
\hline 19 & Oxidation Stress & 57 & 59 & Alzheimer Disease & 18 \\
\hline 20 & Fatigue & 55 & 60 & Antineoplastic Activity & 17 \\
\hline 21 & Herbal Medicine & 46 & 61 & Mental Stress & 17 \\
\hline 22 & Antioxidants & 44 & 62 & Headque & 16 \\
\hline 23 & Drug Structure & 42 & 63 & Cardiovascular Diseases & 14 \\
\hline 24 & Enzyme Activity & 39 & 64 & Immunomodulation & 14 \\
\hline 25 & In vitro Study & 39 & 65 & Gallic Acid & 14 \\
\hline 26 & Rosin & 39 & 66 & Xerostomia & 11 \\
\hline 27 & Drug Response & 38 & 67 & Schizophrenia & 11 \\
\hline 28 & Rhizome & 38 & 68 & Parkinson Disease & 10 \\
\hline 29 & Tyrosol & 38 & 69 & Gastro-intestinal Disease & 9 \\
\hline 30 & Drug Safety & 37 & 70 & Heart Palpitation & 7 \\
\hline 31 & Phenol Derivatives & 36 & 71 & Heart Protection & 6 \\
\hline 32 & Apoptosis & 35 & 72 & Ultraviolet Radiation & 6 \\
\hline 33 & Rosarin & 32 & 73 & Urine Tract Disease & 6 \\
\hline 34 & Neuroprotection & 31 & 74 & Digestive System Disease & 3 \\
\hline 35 & Phytochemistry & 31 & 75 & Heart Muscle Necrosis & 3 \\
\hline 36 & Clinical Trials & 30 & 76 & Gastro-intestinal Disease & 9 \\
\hline 37 & Eleutherococcus Enticosus & 30 & 77 & Heart Palpitation & 7 \\
\hline 38 & Enzyme Inhibition & 30 & & & \\
\hline 39 & Hypercom Perforatum & 29 & & & \\
\hline 40 & Antidepressant Agents & 28 & & & \\
\hline
\end{tabular}

potential and its potential capacity in preventing and treating multiple diseases. In future, more intensive research in needed in discovering its potential therapeutic effects and for developing new formulations.

\section{REFERENCES}

1. Rhodiola rosea. 2019. https://en.wikipedia.org/wiki/Rhodiola_rosea.

2. Singh J. Rhodiola rosea. 2016. Ayurtimes.com/Rhodiola-rosea.

3. Golden root, Rhodiola rosea-Succulent Plant. https://nurserylive.com/buy-plants- by-type-online-in-india/succulent-plants/golden-root-rhodiola-rosea-succulentplant-plants-in-india.

4. Mary B, Jillian ES, Aviva R. Endocrine Disorders and Adrenal Support: Chapter 6. Botanical Medicine for Women's Health. Elsevier Inc. 2010;186-210. https:// doi.org/10.1016/B978-0-443-07277-2.00008-8.

5. Navrátilová Z, Patocka J. Goldenroot L. (Rhodiola rosea L.) in psychiatry [Rozchodnice ružová (Rhodiola rosea L.) v psychiatrii]. Psychiatrie 2016:20(1):23-8.

6. Khanum F, Bawa AS, Singh B. Rhodiola rosea: A versatile adaptogen. Compr Rev Food Sci Food Saf. 2005;4(3):55-62

7. Panossian A, Wikman G, Sarris J. Rosenroot (Rhodiola rosea): Traditional use, 
chemical composition, pharmacology and clinical efficacy. Phytomedicine. 2010;17(7):481-93

8. Shinde J. A miracle herb discovered by DIHAR. 2014. https://www.brandindiapharma.in/ pharmaceutical-blogs/ a-miracle-herb-discovered-by-dihar/

9. Gupta BM, Mueen AKK, Dhawan SM, Gupta R. Aloe vera (Medicinal Plant) Research: A Scientometric Assessment of Global Publications Output during 2007-16. Pharmacogn J. 2018;10(1):1-8.

10. Gupta BM, Mueen AKK. Research on Azadrachta indica: A scientometric assessment of global publications output during 1997-16. International Journal of Pharmaceutical Investigation. 2018;8(4):164-72.

11. Mueen AKK, Gupta BM, Gupta R. Curcuma longa (Medicinal Plant) research: A scientometric assessment of global publications output during 1997-2016. Pharmacogn J. 2018;10(5):998-1006.

12. Gupta BM, Mueen AKK, Gupta R. Glycyrrhiza glabre (Medicinal plant) research: A scientometric assessment of global publications output during 1997-2016. Pharmacogn J. 2018;10(6):1067-75.
13. Gupta BM, Mueen AKK. Research on Nigella sativa: A scientometric assessment of global publications output during 1989-18. Int J Pharm Investig 2018;8(4):173-81.

14. Gupta BM, Gupta R, Agarwal A, Goel S. Ocimum Santum (Medicinal plant) research: A scientometric assessment of global publications output during 2008-17. Int J Inf Dissem Technol. 2018;8(2):67-73.

15. Gupta BM, Dhawan SM, Gupta R. Phyllanthis emblica (Medicinal plant) research: A scientometric assessment of global publications output during 2008-17. EC Pharmacol anbd Toxicol. 2019;7(1):18-28.

16. Gupta BM, Mueen AKK, Gupta R. Global research on Tinospora Cordifolia (Medicinal Plant) with special reference to India: A Scientometric Assessment Publications Output during 2001-16. International Journal of Pharmacognosy and Chinese Medicine. 2018;2(4):1-11.

17. Gupta BM, Mueen AKK. Research on Withania somnifera (Ashwaganda): A scientometric assessment of global publications Output during 1995-18. Int J Pharm Investig. 2019;9(3):59-66.

Cite this article: Ahmed KKM, Gupta BM, Bansal J, Bansal M. Rhodiola rosea: A Quantitative and Qualitative Assessment of Global Publications Output during 2003-18. Int. J. Pharm. Investigation. 2019;9(3):93-100. 